\title{
Card Mapper
}

\author{
Enabling Data-Driven Reflections on Ideation Cards \\ Dimitrios Darzentas ${ }^{1}$, Raphael Velt $^{2}$, Richard Wetzel ${ }^{3}$, \\ Peter J. Craigon ${ }^{1}$, Hanne Wagner ${ }^{1}$, Lachlan Urquhart ${ }^{4}$, Steve Benford ${ }^{1}$

\begin{tabular}{|c|c|c|c|}
\hline $\begin{array}{l}\text { University of Nottingham }{ }^{1} \\
\text { Nottingham, UK } \\
\text { \{firstname.lastname\} } \\
\text { @nottingham.ac.uk }\end{array}$ & $\begin{array}{l}\text { Breda University of } \\
\text { Applied Sciences }^{2} \\
\text { Breda, Netherlands } \\
\text { Velt.R@buas.nl }\end{array}$ & $\begin{array}{c}\text { Lucerne University of Applied } \\
\text { Sciences and Arts }{ }^{3} \\
\text { Lucerne, Switzerland } \\
\text { Richard.Wetzel@hslu.ch }\end{array}$ & $\begin{array}{c}\text { University of Edinburgh }{ }^{4} \text {, } \\
\text { Edinburgh, UK } \\
\text { Lachlan.Urquhart@ed.ac. } \\
\text { uk }\end{array}$ \\
\hline
\end{tabular}

\begin{abstract}
We explore how usage data captured from ideation cards can enable reflection on design. We deployed a deck of ideation cards on a Masters level module over two years, developing the means to capture the students' designs into a digital repository. We created two visualisations to reveal the relative co-occurrences of the cards as concept space and the relative proximity of designs (through cards used in common) as design space. We used these to elicit reflections from the perspectives of students, teachers and card designers. Our findings inspire ideas for extending the data-driven use of ideation cards throughout the design process; informing the redesign of cards, the rules for using them and their live connection to supporting materials and enabling stakeholders to reflect and recognise challenges and opportunities. We also identified the need, and potential ways, to capture a richer design rationale, including annotations, discarded cards and varying card interpretations.
\end{abstract}

\section{CCS CONCEPTS}

- Human-centered computing

Human computer interaction (HCI)

\section{KEYWORDS}

Design; Ideation Cards; Concept Space; Configuration Space; Design Documentation; Design Rationale; Design Fixation;

\section{ACM Reference format:}

Dimitrios Darzentas, Raphael Velt, Richard Wetzel, Peter Craigon, Hanne Wagner, Lachlan Urquhart, Steve Benford. 2019. Card Mapper: Enabling Data-Driven Reflections on Ideation Cards. In 2019 CHI Conference on Human Factors in Computing Systems Proceedings (CHI 2019), May 4-9, 2019, Glasgow, Scotland, UK. ACM, New York, NY, USA. 10 pages. https://doi.org/10.1145/3290607.XXXXXXX 1234567890

\section{INTRODUCTION}

Physical design cards such as ideation cards, method cards, envisioning cards and variants of these have emerged as a popular means of supporting the early stages of design across many domains. Studies within HCI have revealed how despite - or perhaps due to - their lack of digital functionality such cards are felt to be inspiring, flexible, informative, focusing and collaborative.

Over several years we used ideation cards to teach university students about mixed reality game design. This led to the realisation that the cards might also enable us to capture valuable data about the design process that could support reflection by various stakeholders including designers, design facilitators and also card designers. Specifically, by tagging generated designs with the cards that informed them, we could build up a repository of designs and associated metadata that would help us reflect on how the cards were used, answering questions such as: Which cards are popular? Which tend to co-occur? Which are hardly used? Are there groups of designs that share common cards and others that use only distinct cards? Put more formally, we suspected that a data-driven approach for reflecting on the use of physical design cards might help us better understand the relationship between what has been referred to as 'Concept Space' - the range of concepts available to designers (our students) as embodied by the cards - and 'Configuration Space' - the range of designs that they help produce [28]. This might then enable us to better appreciate how designers think (for example are they fixated?), how facilitators (e.g. teachers) support them, and how the cards themselves might be extended and augmented.

In what follows, we describe how we built a prototype called Card Mapper that enabled us to capture such a design repository and visualise its concept and configuration spaces, and how, with choosing design education as the practical context, we then used this to elicit reflections from the students and teacher on our 
course as well as from the original designer of the cards we used. Our findings lead us to suggest that usage data captured from ideation cards can extend their utility throughout the design process. Our approach enables them to be enhanced and digitally augmented in various ways, but also highlights the need to capture richer details on design rationale which furthers our interest in encouraging reflections of card use in the design process, and how this reflection can feed back into card design, content and augmentations.

\section{STUDYING PHYSICAL DESIGN CARDS}

Physical ideation cards have an established lineage in HCI as a tool for sensitising designers to new, complex ideas in a structured and yet flexible way. Card based approaches go by a range of names from 'ideation' cards [23] and 'methods' cards [57] to 'envisioning' cards [21], and 'pattern' cards [51]. Despite such a broad nomenclature, these all aim to help structure thinking around complex themes during the design process. Such cards have been put to a wide variety of uses including: supporting the design of mixed reality games [53], exertion games [40] and sound design in games [2]; architecture [19] designing IoT systems [39]; raising awareness of cybersecurity, threats [18] and privacy $[4,35]$; promoting value centred [21] and ethical [56] design; stimulating creativity in design [23]; and encouraging new methods [23].Previous studies of cards in HCI have focused on how decks of cards were developed, including their content, visual design, and the rules for using them [2,17,34]; providing guidance on how to create them [33]; discussed user satisfaction and their perceived usefulness in specific design contexts [39,40,51]; considered their use in translating concepts and principles from other fields $[21,35,56]$; and offered broader reflections on how cards support design in general, including the importance of physicality [17], their inherent playfulness [10,30], what makes them inspiring $[25,27,31,53]$, how they promote and structure discussion [27], and how they provide knowledge and focus [40]. While these studies have involved quantitative as well as qualitative data, little has been reported about patterns of card usage and their effect on the resulting designs. There are examples of cards being used in an educational context $[9,15]$, however they do not include data-driven reflection on their use.

We have found two examples that do follow such an approach to some extent. Firstly, in a study of a deck of 14 Exertion Cards [40], 22 teams of designers engaged with the cards and produced one design each. Participants then rated the 14 cards as "useful/not useful". For example, one card was rated as 'not useful' by six teams, while one team rated nine cards as 'not useful'. The authors concluded that not all cards were equally useful for all designs, and giving them valuable feedback about their card designs: "Effort Interpretation and possibly Physical Contention were the cards that received the most (although still modest) count of 'not useful', suggesting that in future iterations of the cards, these cards should be refined first." A second example concerns the "Sound Design in Games" deck of cards [2]. Here, the authors meticulously tracked the use of all cards throughout one design session: when was a card played, discussed, and discarded and how it influenced the idea. This allowed the authors to better understand how idea unfold and reveal a problem with what they call 'aggregator cards' that cover broad concepts. Both of these studies exemplify how a datadriven approach can deliver valuable insight to card designers for improving their decks. We build on this approach by exploring the further benefits that might arise if card users (and their facilitators) could also draw on such data.

\section{APPROACH}

Inspired by the literature and by our own experience of using cards we report how we explored data-driven reflections on the use of ideation cards. With the intention of gathering data and insights, we created an open-ended prototype system, called Card Mapper, comprised of web and augmented reality interfaces. These were for capturing visual design sketches that consist of cards (or images of them), entering them into a repository, recording data about the cards that each design uses, and then being able to visualise the resulting relationships between cards through the designs they share in common and vice versa.

Card Mapper enabled us to self-reflect on how we had used the cards in our own teaching. This reflective process was initiated by the teacher, who then reached out to the original designer of the cards (at a different institution) and then the students who had previously taken the course in order to broaden the range of perspectives involved. Reflections between the teacher and card designer (and wider research team) were iterative, involving a series of discussions during which the prototype was refined and extended. Students were invited back to take part in a workshop (at which neither the teacher nor card designer were present) to capture their views. The students' views were independently 
written up after the workshop while the teacher and card designer wrote up their own reflections. Both teacher and card designer are authors of this paper so that what follows is largely a self-reflexive account rather than a formally structured study. We refer to them by their roles where relevant, while they are also present in the 'we' that is the overall research team.

The following section briefly introduces the pre-existing deck of Mixed Reality Game Cards to help appreciate the detail of our findings. We then explain how we used them in our teaching; introduce the Card Mapper prototype; and present the reflections of those involved.

\section{THE MIXED REALITY GAME CARDS}

Mixed reality games combine real environment with digital content. Examples include location-based games such as Geocaching [41,42], Zombies, Run! [46] and Pokémon Go [43]; mobile augmented reality games such as ARQuake [48] or TimeWarp [8]; and artist-driven experiences like Can You See Me Now? [6]. We employed a previously designed and well-used deck of ideation cards for teaching the design of such games known as 'The Mixed Reality Game Cards' [53]. These cards distilled key guidelines from the literature (e.g. [16,38,47,52]) before being iteratively refined through use by over 200 game students, industry experts, experienced academics and artists. We were therefore dealing with an established, comprehensive and widely used ideation deck.

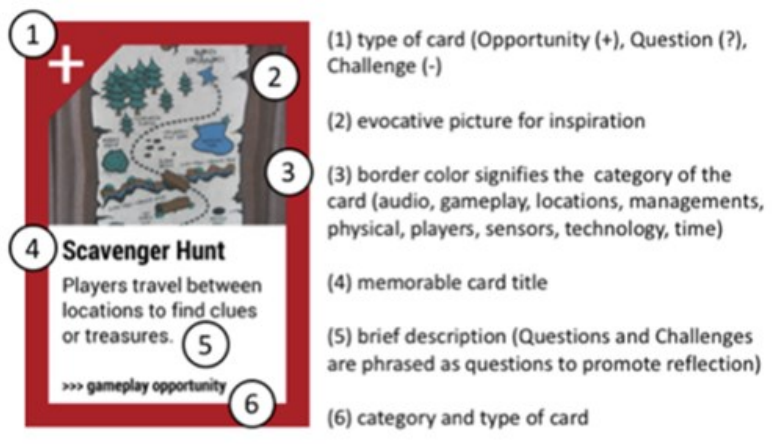

Figure 1. Example Opportunity Card with labels.

The deck comprises 93 cards and has a distinctive structure in which each card is classified as belonging to one of nine categories and one of three types. The categories define thematic groupings of cards into: gameplay, players, physical, technology, sensors, audio, locations, management and time. In contrast, the types suggest the role of the card in the design process and include: 51 Opportunity cards that represent the basic building blocks of a game; 18 Question cards that pose key questions to encourage reflection and provoke discussion; and 24 Challenge cards that confront the designer with accumulated knowledge of common design problems from the field. The deck also contains blank cards so that users can add their own material. (When referred to in the paper, the names of the individual cards are in denoted in small capitals.)

The cards come with a set of rules that suggest how they can be used in design sessions. For example, users may begin with quick-fire design games in which they randomly draw three Opportunity cards and rapidly think of a corresponding idea (a method reminiscent of VNA Cards [30] and PLEX Cards [34]). This is followed by further rounds that enrich a selected idea with more opportunities, before then questioning and challenging their idea using the other types of cards. Finished designs are often captured in the form of posters with cards spatially laid out and annotated with notes and scribbles (see Figure 2 for a design example). Overall, the Mixed Reality Game Cards resemble both additive and idea generating decks $[3,30,34]$ as well as more introspective ones [27,45]. Figure 1 shows a sample card and explains the different design elements.

\section{TEACHING WITH THE CARDS}

The cards were used on a Computer Science Masters course called Mixed Reality Technologies (MRT) that covers the principles and technologies of mixed reality, virtual reality, augmented reality, locative media and also ubiquitous systems from an HCI perspective, including introducing design concepts and prototyping technologies. A further goal of the course is to expose the students to design thinking and methods, including techniques for creative ideation, hence our use of the cards. Around two thirds of the students are Computer Scientists while the remaining third have signed up for a programme in HCI. The course is entirely assessed by practical work, half of which involves designing and prototyping a mixed reality experience to a design brief set by the teacher. $10 \%$ of this total course mark was awarded for generation of the design idea using the cards. For the cohorts from two consecutive runs of the course that we consider in this paper, the brief was to design a mixed reality game for visitors to the university campus (2017) and to a museum, historical site or other heritage attraction to be chosen by the student (2018). The content of lectures, course support material, instructions, teaching support and assessment were broadly the same across the two years. 


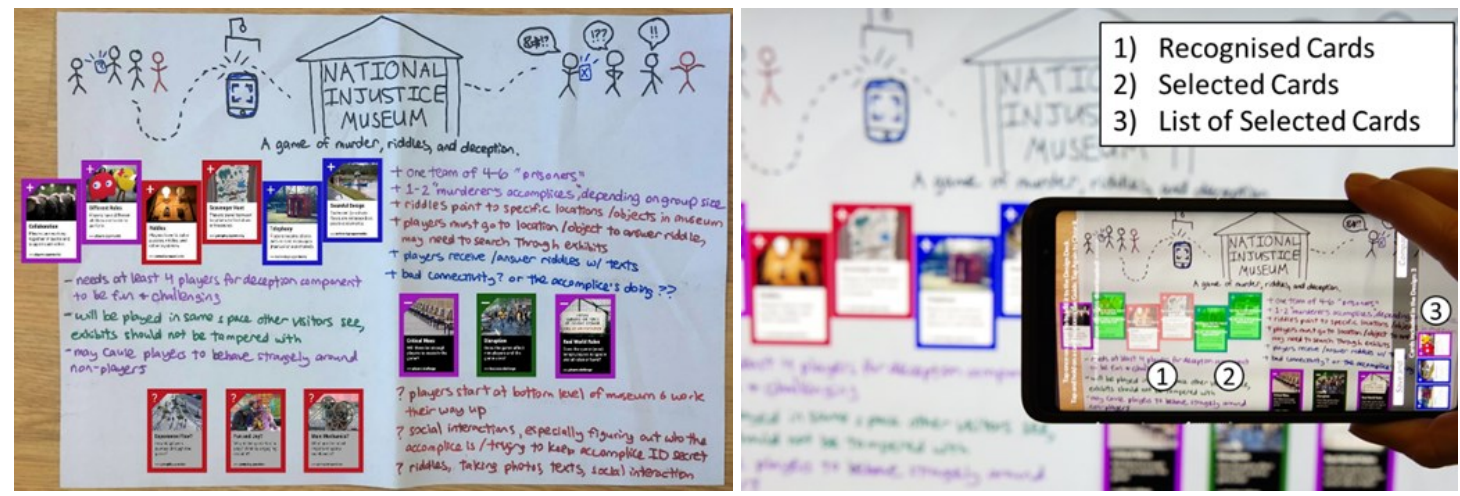

Figure 2. (Left) An example of a rich student design in the form of a poster using the Mixed Reality Cards.

(Right) The same design being scanned into the repository using the Card Mapper AR scanner app.

For example, in 2018 the brief was "to create a mixed reality game that can be played using a mobile device while exploring a museum and/or its grounds" and the students were explicitly told to "use mixed reality game ideation cards to create an interesting and appropriate game design" where assessment criteria included "creativity and appropriateness of the design alongside an explanation of the ideation process using the mixed reality game ideation cards". Students first worked in groups using the cards as described above so as to get familiar with them. They were then given several weeks to work on their own designs individually and were told they could use the cards however they liked, but must generate a concept sketch that was 'tagged' with images of the cards along with explanatory annotations. They were given digital copies of the cards to support this. Each submitted design was marked by the teacher (subject to internal and external moderation to validate appropriateness, fairness and conformance to the published rubric) and feedback was given. Additional teaching support included seven onehour long lectures covering key concepts and five twohour long lab sessions to cover design and prototyping tools, including two that introduced the ideation cards and enabled the students to practice using them in groups.

\section{THE CARD MAPPER PROTOTYPE}

With the course having been run for two years, we collected more than 100 designs, each tagged with a set of cards that might potentially be a useful source of data for reflecting on the use of the cards. We therefore implemented Card Mapper as a technological prototype to help us explore this data. Card Mapper has two key functions. The first is to capture designs (expressed as either physical or digital concept sketches), into a structured repository. The second is to provide visualisations to explore the repository.

\subsection{Capturing design information}

The first component of Card Mapper is a web-based tool that serves as both the repository for the designs and the main management interface. This is built around a database which holds extensible definitions for ideation cards, decks of ideation cards and designs. Card designers are able to upload definitions of their ideation decks, including images and basic metadata for each card in the deck. The database holds lists of cards arranged in decks, but primarily contains designs, which are composed of one or more cards from a single deck. There are two methods for uploading designs. One is to use a manual web interface to upload a pictorial overview of the design (as the students were asked to produce), which usually consists of a spatial arrangement of some of the cards on a sketch, poster or even just on a table, featuring the cards and annotations. Once the picture has been uploaded, the designer can use a straightforward click-and-drag interface reminiscent of adding pins to a map to drag virtual versions of each card onto the image and so tag it. By doing so they mark-up the design sketch with the relevant cards and an entry is made in the design database, containing the listed cards and any other listed metadata.

While this method is effective, it is also time consuming and reliant on the willingness and diligence of the designer to complete successfully. We therefore introduced a second method in the form of the augmented reality 'scanner' mobile interface shown in Figure 2. The scanner is an Android and iOS mobile app to support 'digitising' designs. It utilises reliable 2D image target tracking to accurately recognise and track the cards in a given ideation deck. Essentially, when the design session is complete, the app is used to quickly 'scan' the presence of the final choice and arrangement of cards, whether as a spatial arrangement, poster or other design artefact, which 
it can then automatically upload to the design database, thus semi-automating and considerably speeding up the process of collecting the designs. Between the two input methods described above, we populated the repository with a total of 113 individual designs from the MRT student coursework over the two years. Any deck of cards can be potentially used in such a way, and we have added several decks to other and newer versions, however we limited this research to the MRT deck. We exported a dataset from the repository listing the details for each uploaded design including: its name, cards used, and the mark awarded by the teacher.

\subsection{Visualising Concept and Configuration Spaces}

We then set about developing interactive visualisations of the repository. We chose to work with visualisations as we felt that these would enable the kinds of open-ended exploration of the design repository and questioning of the potential role of card data that were required of a prototype, rather than trying to generate metrics and statistics too early on which might close off such exploration. The dataset was therefore imported into the Open Graph Visualisation platform Gephi [5]. Following some experimentation, we alighted on two visualisations that correspond to Concept Space and Configuration Space as defined in [28]. Concept space defines the space of concepts that designers work with, which in our interpretation was taken to be the deck of MRT cards. Configuration Space describes the set of designs that they produce as a result, in this case the collection of students' designs. We chose these visualisations as they reveal the strength of mutual associations between and across the cards and designs.

Figure 3 (Left) above provides an overview of Concept Space. We appreciate that the labels are not readable at the size and scale and the interested reader is directed to the high-resolution images provided in the supplementary material for closer examination. Each card in the MRT ideation deck is represented by a unique node, with the radius signifying the number of times it has been used across all designs as 'popularity'. As some cards were not used at all, a minimum value was given. The range was adjusted for visibility. The colour denotes the category, matching that of the cards. The bidirectional edges between cards denote co-occurrences, meaning the instances where the two cards were included in a common design, with the weight (thickness) of the edge denoting the number of times this occurred across all the designs in the repository. The layout of the nodes was achieved using the Fruchterman-Reingold [22] force-directed layout algorithm based on the node sizes and edge weights. This results in the cards that are more commonly used (and hence also more tightly interlinked), moving to the centre of the visualisation. Individual nodes can be selected to reveal information about the card including details of which other cards it is connected to and which student designs it is used in. Figure 3 (Right) also provides a corresponding overview of Configuration Space.

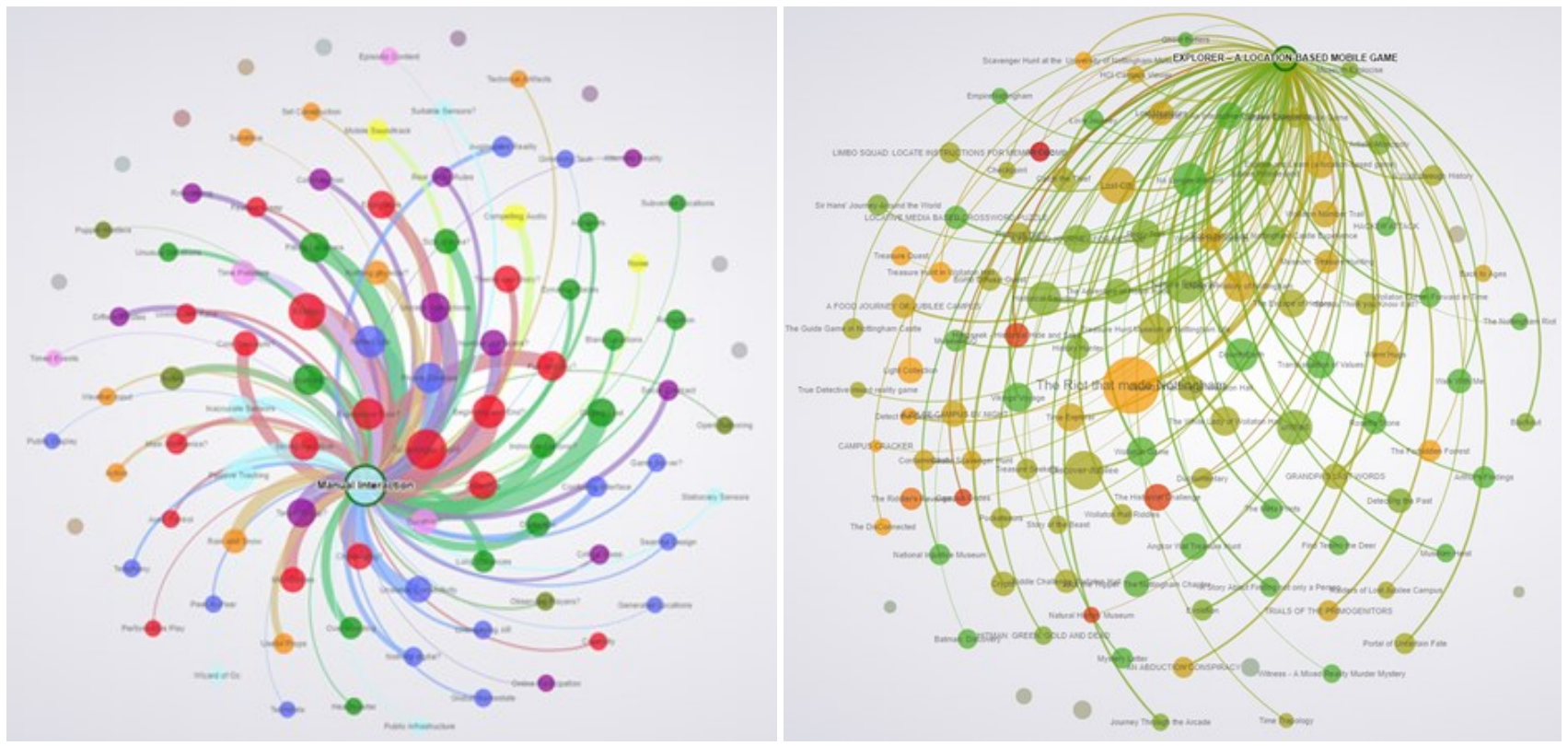

Figure 3. (Left) Visualising Concept Space as the popularity and co-occurrences of cards. (Right) Visualising Configuration Space as the relatedness of designs, number of cards they used and their scores. 
Each node depicts a single design created by a student with its radius depending on the number of cards it used. Its colour denotes the relative marks awarded by the teacher running from the lowest (bright red) to the highest (bright green). Bidirectional edges connecting two designs denote that they shared at least one card in common, with their weight corresponding to the number of matching cards. Again, the Fruchterman-Reingold force-directed algorithm is used to layout the designs so that those that are more tightly interlinked by sharing many common cards move to the centre.

\section{ENGAGING STAKEHOLDERS IN MAPPING CARDS}

We used Card Mapper to probe the opportunities and challenges of introducing card usage data into the design process. Three kinds of stakeholder were involved in a reflexive exercise: students (designers), teacher (facilitator) and the card designer. As noted above, this process was iterative. For the sake of clarity, we now present their reflections as a series of layers, first exploring the student's view, next the teacher's reflections on this and their own view, and then doing the same for the card designer.

\subsection{The student's perspective}

We held a workshop with a group of 7 students, who had used the ideation cards as part of their classes and coursework. The group was self-selecting, responding to an invite issued through institutional email lists. All 7 had achieved among the higher grades on the course. The workshop consisted of four parts of written and spoken discussion. First, participants were invited to recall and reflect on their use of the cards during the course. This was followed by two exercises focusing on exploring the different visualisations. The workshop closed with a final discussion and reflection on the usefulness of the visualisations. At the outset some of the students explained that, following the initial use of the cards in lab classes, they had independently come up with game ideas and returned to the cards to help develop these into concept sketches. Thus, as the students described it, the cards had a structuring and elaborating role to refine and critique their idea within the design process as well as an ideation one to create the initial concept.

The Concept Space visualisation helped elicit accounts of the students' design rationales. When asked to explain why the visualisation looked as it did, the overwhelming response was that the pattern of card usage reflected the constraints introduced by the assessment and the tools available to them for subsequently developing a prototype. The coursework prescribed the development of an experience for a heritage site, such as a museum or the university campus. In addition, two prototyping technologies were specifically covered in the course. One a location based triggering technology and the other a technology similar to $\mathrm{QR}$ codes to activate and trigger elements of the experience. These were used to explain the relative use of the cards and their position in the visualisation. For example, one participant indicated that the imprecision of the location-based technology required moving from room to room in a museum to operate reliably, a mechanic that lent itself to a SCAVENGER HUNT experience. The use of $\mathrm{QR}$ type codes necessitated MANUAL INTERACTION resulting in the prominence of that card. The necessity of engaging visitors brought the NUMBER OF PLAYERS card to prominence. These constraints were also used to explain the relatively low usage of some other cards. For example, SET CONSTRUCTION was thought not to have been appropriate within a museum. Other participants also explained that certain cards such as ACTORS and WIZARD OF OZ would have demanded too much time and resource. Inspection of the outer edges of the visualisation revealed the 'blank' cards in the deck had hardly ever been used. When asked why, the students responded that they were not confident enough to challenge the existing set of concepts in their coursework.

The visualisation prompted one participant to reflect on her use of a card which had been little used by other students, TELEPHONY. She explained how the location she wished to use meant that there was unreliable phone signal. This meant that she had to consider the mechanics of her experience and chosen technology. Based on experience of other games she integrated the unreliability of communication into her experience thereby turning a potential problem caused by location and technology into an opportunity to enhance the experience's mechanic. This explanation indicates the level of contextual detail necessary to fully understand the use of a card in a design and highlights how a visualisation can prompt an explanation from the designer. The cards SEAMFUL DESIGN and UnSTABle CONNECTIVITY could have likewise expressed this sentiment, but were not chosen by the student, illustrating the non-deterministic nature of the cards and their meaning.

Interpreting the Configuration Space visualisation proved more challenging and the students found the lack of contextual information impeded their ability to fully 
understand the relationship between their design and others. It was difficult to immediately ascertain which cards were the source of links between designs. The desire to know how the cards were used was also prominent. For example, how a card was applied to a type of game experience, and also whether the concepts of some cards were considered positively as enablers, or negatively as issues to be overcome. Such knowledge was considered important in understanding the genuine similarity between designs. In addition, it was voiced that showing the relative mark might make participants uncomfortable, especially when being potentially shared with third parties, and was thought to not necessarily represent the quality of the design. Despite the missing information, one participant was pleased to see that their design was on the edge of the visualisation as this suggested that it was relatively unique, while also allowing them to find links with other designs. They had created a 'treasure hunt' type game and the visualisation revealed potential connections to other 'murder mystery' type games that they thought might be useful to view were they to design further games. The students commented that seeing such data beforehand would not fundamentally change what they did, but rather might help them refine or improve their design perhaps by adding a less used card. One participant noted that the data would be "better to use in the process of improvement rather than design." Another thought that the use the data beforehand "would completely go against ideation" by influencing the process. Others thought that it could be a guide to the "path of least resistance", by highlighting combinations of cards that work well together and gain a good mark.

Whilst much of the discussion in response to the data focused on how it reflected the constraints of the assessment, it is important to note that this did not diminish the cards ability to aid students to be creative and help them make their designed experience, with students remarking how they would also be useful when one did not have an initial idea. They valued and enjoyed using them as a tool in designing their experience, which was also shown by the fact that one student actually gave her cards to friend who used them to create his own role play gaming scenarios.

\subsection{The Teacher's Perspective}

The teacher explored the visualisations and reflected on the students' comments. They agreed that the nature of the brief and availability of prototyping tools influenced the student's choice of concepts and hence cards with the implication that they might broaden the range of available tools in the future. However, they disagreed on some points, for example feeling that SET CONSTRUCTION and LOCATIONS were relevant cards to the brief (museums construct sets as part of exhibits and include a variety of indoor and outdoor locations that need careful consideration) and with hindsight would now address these points in lectures. Thus, the students' comments on specific cards provided valuable feedback for reflecting on how key concepts might be better taught. The comments led to the realisation that the teacher had instructed the students to justify the cards used in the assessment but had not asked them to account for cards they had considered but rejected. The teacher felt that rejection might be a telling indicator of how a concept had been understood. Accounts of rejected cards might have been requested in the brief or gathered from the use of the visualisation in a post-design reflection as the students had evidently done.

The teacher then used Card Mapper to undertake their own review of the coverage of the cards in relation to course content: how did the students' use of the cards reflect the material delivered in lectures and what implications might this have for redesigning the course? Inspection of the Concept Space visualisation revealed that Gameplay themed (red) cards had proven especially popular with the students. This was perhaps unsurprising given that the brief required the students to design a game, but it was also notable in that game design had not explicitly been covered on the course which was about mixed reality rather than games specifically. This suggested that students were perhaps using these cards to plug important gaps in their knowledge, raising the question of whether the course should directly cover these concepts, perhaps through an additional lecture. Another possibility would be to more directly connect the cards to support materials in order to support self-directed learning inside and outside of lectures. The teacher also noted that future assessments that did not focus on games would require these popular Gameplay themed cards to be replaced with equivalent domain specific design cards (e.g., for designing wellbeing, smart mobility disaster response or whatever application was chosen as the focus that particular year). Comparison of the visualisation with the lecture schedule also helped the teacher realise that some popular concepts had only been formally covered after the assessment had finished (the popular card RIDDLES and a number of general UX concepts such as EXPERIENCE Flow, BEGINNING AND END and DURATION) with the clear (with hindsight) implication that these concepts might be introduced earlier on. 
Inspection of the visualisation also revealed cards and themes that appeared underused compared to the emphasis that has been given to them in teaching. Cards that addressed the physical aspects of gameplay such as WEATHER, INPUT, VEHICLES and USEFUL PROPS (orange) appeared distinctly underemployed. The teacher felt that these aspects of mixed reality experiences had been emphasised in lectures and supporting materials and speculated that it may be difficult to encourage computer scientists to break away from focusing on digital technologies and to instead consider locations, props and costumes as being important 'real world' resources. The need to further encourage the use of some concepts inspired the idea of directly including thumbnail images of the cards on lecture slides/handouts to prompt students to consider using the cards when they encountered them later. Another implication was to constrain the use of the cards, for example requiring future students to use at least one unpopular but important concept from previous years. Again, with reference to the temporal organisation of the course, inspection of the cards at the fringes of the visualisation revealed some interesting omissions including PUBLIC DISPLAYS, SEAMFUL DESIGN and PERFORMATIVE PLAY that were only covered postassessment.

Finally, the teacher considered how the Configuration Space visualisation might help with the notoriously knotty problem of giving feedback. The visualisation suggested that using large numbers of cards was associated with lower scores, which corresponded to the teacher's view that this might lead to bloated designs that lacked clarity and that would also be difficult to fully describe and justify within the available word count. Using small numbers of cards appeared to be a high-risk strategy, with some very focused designs (in terms of numbers of cards used) achieving very good scores while other fared badly. In general, moderate complexity designs featuring around 10-20 cards, seemed to fare well. The teacher also felt that the visualisation helped identify designs that might be shown to future students as good examples. The current convention is that students' work is generally not published for others to see due to concerns about plagiarism (the teacher was interested to note that the students were uncomfortable with sharing marks). This said, it is not uncommon to publish a few selected examples of best practice, especially if the topic of assessment changes year on year. Using the visualisation helped the teacher identify designs that not only scored highly but that were also spread around. The teacher initially selected the four highest scoring designs as examples of best practice, but then supplemented these with two more chosen from the next band down that extended coverage across the visualisation and so broadened the range of cards that were represented. The long-term aim would be to identify a small set of highquality examples over several years ultimately including every card.

\subsection{The Card Designer's Perspective}

The original designer of the Mixed Reality Game Cards also engaged with our prototype, and noted that both students' and teacher's comments mirrored their own experiences from previous design workshops. The apparent underuse of the Physical category was not a great surprise and they commented that current commercial examples such as Pokémon Go [43] also do not emphasise this issue. Indeed, this is exactly the reason they had included Physical as a separate category in the deck; to encourage designers to consider the possibilities. However, it appeared that this overt intention was not reflected in the students' designs. The observation that using many cards led to low scores validated what the card designer has witnessed in several workshops: that card users are too eager to add cards to their designs without critically reflecting on whether each is a meaningful addition or not.

The card designer also directly explored the two visualisations. Seeing the popularity of cards like SCAVENGER HUNT that appeared in most of the designs, led the designer to the reflection that some cards in the current deck have a far wider scope (are broader in concept) compared to others that are much narrower (e.g., WEATHER INPUT). The high use of the broad concept card might warrant splitting it up into sub-concepts while a card like WEATHER INPUT could be made less specific by having weather just as an example for a potential card like EXTERNAL INPUT. The card designer also inspected the various designs utilising SCAVENGER HUNT to try to ascertain whether there are any distinguishable subgenres, though this proved difficult from the visualisation alone. However, the designer noted that even if one could split SCAVENGER HUNT into appropriate subcategories, this would introduce the danger of then "spamming" the deck with variants of one concept and thus "drowning out" other cards. Here, additional technological support such as digital overlays might provide additional detail on such broad cards, helping the user reflect on subcategories, without the need to include these as separate thereby equally weighted physical cards. 
More surprising to the card designer was the relatively "weak" role that cards of the Location category played. Considering that the brief for the campus experience naturally had a strong spatial element, the card designer would have expected more of these cards to be used. This might hint at some flaws in this area of the deck with cards perhaps not fully covering the necessary design knowledge or doing it in an obvious or too obtuse way.

The relatively low use of important, (in the card designer's eyes) if sometimes niche, cards inspired a further idea. Many decks of game and collectable cards employ scarcity as a mechanism. Why not draw on card usage data to place a scarcity value on each card in the deck as a way of drawing attention to it? This could be supplemented by also extending the rules for using cards in design, for example rewarding players for collecting or even trading scarce and hence valuable design cards.

Like the teacher, the card designer also wanted richer information about the student's design rationale, including cards that had been rejected. Based on their experience of collaborative design sessions in which the relative positions of cards on tables and other shared surfaces seems to reflect their centrality to the design, they wondered whether Card Mapper might also extract useful data about the spatial arrangement of cards. Turning the problem around, the card designer mused whether sketch and poster templates might be designed to encourage the spatial grouping of cards - e.g., inviting cards to be placed in 'critical' versus 'peripheral' versus 'rejected' zones and could such templates be included with the deck and its rules.

\section{INFORMING CARD DESIGN AND USE}

Our probing with Card Mapper revealed diverse opportunities but also challenges for using data captured from ideation cards. We now generalise these ideas away from the specific context of a taught course to explore how such a data-driven approach might enhance the design and use of physical design cards in general, opening up new directions of application and further research.

\subsection{Enabling broader reflections}

As their name suggests, ideation cards have largely been seen as supporting the ideation stage of the design process which has been the focus of most previous studies. Our findings suggest that capturing and reflecting on card usage opens up wider possibilities past this initial stage of the design process. Both the Concept Space and
Configuration Space visualisations helped our students as designers to reflect on their design strategies and compare them to others afterwards. Over a longer timescale, the capture of card usage data alongside specific designs enables an organisation or design community to build up a repository of design knowledge. We saw, for example, how the teacher was able to identify a spread of examples of best practice over two years of using the cards. Designers could use the cards to interrogate the repository, issuing queries such as "show me any designs that our company has previously generated that used this combination of cards".

Like our teacher, those with more strategic, managerial and/or lead design positions could reflect on the overall use of cards by their designers asking questions such as: “what concepts are central to our company's designs and are they well enough supported within the company in terms of training, supporting documentation or prototyping tools?" What concepts that knowledgeable others (card designers) have identified as being important are we ignoring and should we be paying more attention to them? Our study has shown that key to this broader thinking about the role of ideation cards in the design process is to consider the perspectives of different stakeholders. How can data about card usage support designers, design facilitators but also the designers of the cards themselves as we consider below?

\subsection{Enriching the designs of cards}

Data about the usage of cards can directly feed back into the design of the cards themselves. One possibility identified by the card designer was to directly incorporate the data onto the cards themselves, for example through a reflection of scarcity that would give extra "value" to certain cards in a deck. Dynamically generated cards (digital or print on demand) might even incorporate live usage statistics in the style of Top Trumps [58] or grouping cards by rarity similar to card games such as Magic: The Gathering [14]. This use of data can shape the rules for using cards within design sessions, for example by introducing a "wildcard" deck of infrequently used cards that might be brought into play at various stages; conversely having a "banned" deck of overused cards; requiring designers to start with a "rare" card; or scoring whole designs and the combined "value".

More generally, we saw how the card designer was able to reflect on the balance of cards, themes and types within the deck. One of the new ideas to emerge from this was to introduce hierarchical and collapsible subcategories of 
cards so that designers could initially work with a general concept before unpacking it in further detail and to work with sub-concepts later on in the process.

Underpinning the ideas is the approach of designing decks of cards according to a structured metadata scheme (in our case each card corresponds to a key concept, category and type). Most decks of ideation cards already employ basic metadata distinguishing between different groups of topics. However, being more deliberate about emphasising this metadata in a deck (and including more types of metadata) would not only make the cards richer, but it also enables deeper reflection on their use, for example being able to reflect on common or uncommon themes but also on designers' approaches. To go a step further, one can view cards as being direct manifestations of metadata in the design process: by using cards, designers are encouraged to follow a metadata scheme and, by associating their designs with cards, are tagging them with metadata so that they can be part of a searchable and reusable repository. A further use of ideation cards suggested by this idea is to retroactively tag existing designs with relevant concepts to create further design examples. Our teacher's reflection on wanting to be able to mix and match between decks, for example wanting to pull in cards relevant to a specific application, points to a benefit of designing cards to a common metadata scheme: if multiple sets of cards conform to a common overall ontology, then it becomes easier to dynamically assemble bespoke decks to target a specific design problem.

\subsection{Additional information during ideation sessions}

Currently, Card Mapper is a tool that captures a design at the end of an ideation session. However, what if we enabled designers to make use of its underlying functionality while a session is unfolding? An interesting possibility here is to consider the role of augmented reality in connecting physical cards to digital resources and to more dynamic digital data. The same data that allows a deeper reflection post-session could be made available during the ideation session. A similar system has been deployed for designing with design patterns [29], and designers could similarly benefit from instant feedback. This could be made dynamic with visualisations recommending cards that might be used during ongoing ideation and idea development.

A further way of enriching the cards is to directly link them to supporting resources including training materials, the wider literature for detailed definitions, explanations and examples of use, and also curated examples from the design repository itself that illustrate best practice. The teacher's reflections also suggest that such linkages might be bi-directional with materials linking back to the cards themselves, for example including thumbnails on bespoke training materials or perhaps connecting the metadata and keywords appearing on published papers to the metadata scheme used by the cards. The students worked with both physical and digital editions of the cards and found them both useful. Beyond their low cost and easy reproducibility, digital cards can be directly included in design reports facilitating the extraction of usage data through tools such as Card Mapper, and can also convey dynamic data, potentially even being updated live during a design session. However, previous research has revealed that the tangibility of physical cards also brings a distinctive flexibility to share design processes. Physical cards can be easily dealt, sorted, held in the hand, exchanged, redistributed, placed on a table in different piles and so forth, to structure ideas and arguments and link them to concepts and wider discussions [20]. Moreover, they can be readily attached to physical posters along with sticky notes, annotations and the other physical paraphernalia that are prevalent in many creative design settings. Surveys of papers summarise the value of physical cards [44,54] as being: providing a tangible tool in a handy form; providing summaries for designers to readily use; having scope for multiple spatial arrangements; providing a common reference point for teams; structure; help designers think beyond normal ideas.

These observations suggest extending the Card Mapper augmented reality interface to overlay more dynamic digital resources and data onto physical cards including links to supporting materials. Cards are ideal trackable objects for reliable 2D image tracking-based $A R$, an affordance that enabled the Card Mapper mobile interface to capture the designs. The same capability can connect each card to a corresponding guide page or enable physical cards to be used as queries to search the digital repository. An early attempt at such a system has been made by providing digital screens with such information during a session [11]. Other work is looking at how traditional card games can be supplemented with "calm technology" [50], making sure the flow of a play session is not disturbed and the physical quality of the cards is not undermined [12].

\subsection{Capturing design process and rationale}

So far we have reflected on the opportunities raised by the card usage data that we were able to capture from finished 
designs. However, our study also revealed various kinds of missing information that would have been useful to capture. In more general terms, we identified a requirement to better capture design rationale, which can be understood as the 'decision layer' [32] or the 'know why' as opposed to the 'know how' of the designs [49]; the capture of such elements is important for knowledge management, communication within and between teams and for the reflective practice of designers [37]. Figure 2 shows an example of a richly annotated design by one of the students to help illustrate what may be missing. We identify several categories of missing design rationale.

First, our current process only captures the cards that end up being used in the final design, not those that were rejected along the way, either outright or because they didn't make the final cut. This suggests the introduction of explicit discard piles into design 'card games' and the capture of these by tools such as Card Mapper. A variant (certainly viable in educational applications such as ours) might be to deliberately constrain the numbers of cards that can appear in a final design and then get designers to list the cards that were rejected, distinguishing each from near misses, to outright rejections, thus providing more sharpness to our data. We also noted above the possibility to create templates for concept sketches that group cards into zones according to their relevance to the design. Secondly, is the need to capture the reasons why cards were used or rejected. We were able to gather some of this qualitative reasoning by requiring students to reflect on their designs as part of their assessment, although students were not asked for reasons why. However, there is considerable work involved in distilling these accounts into useful insights that can then be associated with particular combinations of cards. This implies the need for more rapid ways to capture design rationale for both accepted and rejected cards throughout the extended design process. We could extend tools such as the proposed AR interface above to capture notes about reasons for accepting or rejecting cards during design sessions, for example as voice annotations when participants explain the reasoning to each other. Another possibility is to extend the Concept Space and Configuration Space visualisations to become a general design review tool that allows teams to review and compare designs later and to capture their design rationale as annotations at that point. A third category of missing information that is difficult to capture is missing concepts: what if designers include concepts in their designs that are not reflected in the current card deck? One solution lies in the use and capture of blank cards.
Although our students did not make use of them, our deck includes blank cards that can be filled in by designers. Facilitators might encourage the routine use of such cards as a way of community-sourcing concepts for new cards. Furthermore, depending on the nature of the deck used and its ideation process, it may be useful or even critical to capture the order with which cards are introduced to the design [3]. Other important information is encoded in the spatial layout of the final design (Figure 2), which may have been used by designers to denote some property or value, such as a ranking, or notional groupings. Some card designers provide a type of placemat with their decks with zones of different meaning [39]. Here, one needs to consider the benefit of more structured and similarly arranged designs and restricting the freedom and expression of the designers. Overall, the inclusion of such elements would potentially help to integrate the capture of design rationale into the design process, an important factor in from the point of view of design rationale experts $[24,32,36]$.

\subsection{Addressing design fixation and sharing}

For our final theme, we broaden out our discussion to consider the challenge of design fixation. This refers to the "blind, and sometimes counterproductive, adherence to a limited set of ideas in the design process" and can be characterised as the breadth or otherwise of the mapping between Concept Space and Configuration Space [28]. In reviewing recent research into design fixation, Crilly and Cardoso observe that many studies are really concerned with 'ideation fixation' in the early stages of design [13], which renders our approach to capturing of ideation cards particularly appropriate. Our Card Mapper system can be seen as an attempt to address some of the key challenges of design fixation research posed by their review. For example, they advocate for the development of tools to allow for real time capture of design fixation as well as 'fixation metrics', 'objective measurement,' 'methodological transparency,' and 'procedural consistency' all elements that the Card Mapper has the potential to address in the long term. In looking to the future, [13] ask the questions: "What tools could be developed to better support designers in avoiding or overcoming fixation? Can tools be developed to provide designers with feedback on when they are becoming fixated? What tools might cause or exacerbate fixation and how might those tools be redesigned to change this?" The Card Mapper tool, used in real time to capture data from the transparent consistent, process of using a set of 
ideation cards brings the potential to reveal, explain and challenge design fixation as we now discuss.

We suggest that visualising card usage data might help reduce the problem of design fixation by making visible both Concept and Configuration space. Our visualisations of Concept Space reveal those concepts that appear to be more central to our designers' collective thinking versus those that are more peripheral in terms of employing unusual concepts whereas our visualisations of Configuration Space points towards designs that are more mainstream versus those that may be more edgy. Both may help answer the questions as to whether designers suffer from design fixation and also what might they be fixated on? We suggest that such visualisations can also enable reflection at both an individual and community level - our students appreciated seeing how central their designs were in relation to their peers while the teacher was more concerned about how widely the students had utilised the space of relevant concepts as a group. Our stakeholders' reflections also revealed various strategies for potentially addressing design fixation including: altering the rules to force designers to work with peripheral concepts and/or discard central ones; reconfiguring supporting materials and training; and identifying underlying constraints that shape thinking (e.g., the availability of prototyping tools).

However, our studies also reveal that sharing usage data with the wrong message at the wrong time, for example early on in the ideation process, might actually serve to increase design fixation if it simply encourages designers to copy elements of each other's ideas. In short it is important to consider what usage data is shared with whom at what point of the process. Our teacher and students were cautious about sharing individual designs and scores during the process and to some extent afterwards, with the teacher deciding on a curated approach in which a few examples of best practice might be identified and shared with future students. Similar constraints may or may not be present in commercial design situations due to internal and even external competition. Looking beyond 'horizontal' sharing among peer designers we might also consider 'vertical' sharing' in which different stakeholders share data and hence insights. Some more open design communities might share data and designs more widely between organisations, for example in third sector and public environments when openness is encouraged and sometimes even mandated. With permission, card designers might harvest card usage data to help inform the design of future cards. It is therefore a key challenge for future work to explore the extent to which different stakeholders might be willing to share design data and at what level of detail, from knowledge of the use of cards through to summaries of their rationale, through to actual designs themselves.

\section{CONCLUSION}

While many decks of ideation and related types of cards have been developed for diverse purposes, we know relatively little about how they shape the design process. Inspired by our experience of teaching with the deck of Mixed Reality Game Cards over several years, we realised that there might be great potential in capturing data about card use and feeding it back to designers, facilitators and card designers. Card Mapper represents a first step towards doing this - an initial technological prototype that enabled us to explore both the opportunities and challenges that such data might entail. Feedback from different stakeholders revealed a wide range of potential uses of such data throughout the design process from informing the design of the cards themselves, the rules for using them and connected them to supporting resources; to enabling stakeholders to reflect on the challenge of design fixation and prompting them to consider unusual concepts. However, we also revealed that capturing basic data about which cards are used in which designs is insufficiently rich and that what is required in the future is better ways of capturing broader design rationale, including which concepts were rejected by designers. We hope that our findings will help enrich and extend the use of ideation and other kinds of design cards in the future. Furthermore, we believe that our data-driven approach would also be compatible with other ways of structuring and analysing designs such as design patterns [1,7], strong concepts [26], or ontologies [55].

\section{ACKNOWLEDGMENTS}

We gratefully acknowledge the support of the following Grants from the EPSRC: Living with Digital Ubiquity (EP/M000877/1); EPSRC Centre for Doctoral Training in My Life in Data (EP/L015463/1); From Human Data to Personal Experience (EP/M02315X/1). This project has received funding from the European Union's Horizon 2020 research and innovation programme under grant agreement No 727040 


\section{REFERENCES}

1. Christopher Alexander, Sara Ishikawa, Murray Silverstein, Max Jacobson, Ingrid Fiksdahl-King, and Shlomo Angel. 1977. A Pattern Language: Towns, Buildings, Construction. Oxford University Press, New York.

2. Valter Alves and Licinio Roque. 2011. A Deck for Sound Design in Games: Enhancements Based on a Design Exercise. In Proceedings of the 8th International Conference on Advances in Computer Entertainment Technology (ACE '11), 34:1-34:8. https://doi.org/10.1145/2071423.2071465

3. Valter Alves and Licinio Roque. 2011. An Inspection on a Deck for Sound Design in Games. In Proceedings of the 6th Audio Mostly Conference: A Conference on Interaction with Sound (AM '11), 15-22. https://doi.org/10.1145/2095667.2095670

4. David Barnard-Wills and Debi Ashenden. 2015. Playing with Privacy: Games for Education and Communication in the Politics of Online Privacy. Political Studies 63, 1: 142-160. https://doi.org/10.1111/1467-9248.12049

5. Mathieu Bastian, Sebastien Heymann, and Mathieu Jacomy. 2009. Gephi: An Open Source Software for Exploring and Manipulating Networks. Retrieved September 18, 2018 from http://www.aaai.org/ocs/index.php/ICWSM/09/paper/view/1 54

6. Steve Benford, Andy Crabtree, Martin Flintham, Adam Drozd, Rob Anastasi, Mark Paxton, Nick Tandavanitj, Matt Adams, and Ju Row-Farr. 2006. Can You See Me Now? ACM Trans. Comput.-Hum. Interact. 13, 1: 100-133. https://doi.org/10.1145/1143518.1143522

7. Staffan Björk and Jussi Autor Holopainen. 2005. Patterns In Game Design. Cengage Learning.

8. Lisa Blum, Richard Wetzel, Rod McCall, Leif Oppermann, and Wolfgang Broll. 2012. The Final TimeWarp: Using Form and Content to Support Player Experience and Presence when Designing Location-aware Mobile Augmented Reality Games. In Proceedings of the Designing Interactive Systems Conference (DIS '12), 711-720. https://doi.org/10.1145/2317956.2318064

9. Nis Bornoe, Anders Bruun, and Jan Stage. 2016. Facilitating Redesign with Design Cards: Experiences with Novice Designers. In Proceedings of the 28th Australian Conference on Computer-Human Interaction (OzCHI '16), 452-461. https://doi.org/10.1145/3010915.3010921

10. Eva Brandt and Jörn Messeter. 2004. Facilitating Collaboration Through Design Games. In Proceedings of the Eighth Conference on Participatory Design: Artful Integration: Interweaving Media, Materials and Practices - Volume 1 (PDC 04), 121-131. https://doi.org/10.1145/1011870.1011885

11. Jacob Buur and Astrid Soendergaard. 2000. Video Card Game: An Augmented Environment for User Centred Design Discussions. In Proceedings of DARE 2000 on Designing Augmented Reality Environments (DARE '00), 63-69. https://doi.org/10.1145/354666.354673

12. Gifford Cheung, Alison Lee, Kevin Cheng, and Hae Jin Lee. 2013. Dispensable, Tweakable, and Tangible Components: Supporting Socially Negotiated Gameplay. Games and Culture $\quad 8, \quad 4: \quad 259-288$. https://doi.org/10.1177/1555412013496893

13. Nathan Crilly and Carlos Cardoso. 2017. Where next for research on fixation, inspiration and creativity in design?
Design Studies $\quad 50: \quad 1-38$.

https://doi.org/10.1016/j.destud.2017.02.001

14. Paul A. Crutcher. 2017. Magic: The Gathering. Americana: The Journal of American Popular Culture, 1900 to Present; Hollywood 16, 1. Retrieved September 20, 2018 from https://www.questia.com/library/journal/1P41983157324/magic-the-gathering

15. Shanna R Daly, James L Christian, Seda Yilmaz, Colleen M Seifert, and Richard Gonzalez. Assessing Design Heuristics for Idea Generation in an Introductory Engineering Course. 13.

16. Ola Davidsson, Johan Peitz, and Staffan Björk. 2004. Game Design Patterns for Mobile Games. Project report to Nokia Research Center. Retrieved from http://web.science.mq.edu.au/ isvr/Documents/pdf\%20files/g ame-master/Game_Design_Patterns_for_Mobile_Games.pdf

17. Ying Deng, Alissa N. Antle, and Carman Neustaedter. 2014. Tango Cards: A Card-based Design Tool for Informing the Design of Tangible Learning Games. In Proceedings of the 2014 Conference on Designing Interactive Systems (DIS '14), 695-704. https://doi.org/10.1145/2598510.2598601

18. Tamara Denning, Adam Lerner, Adam Shostack, and Tadayoshi Kohno. 2013. Control-Alt-Hack: The Design and Evaluation of a Card Game for Computer Security Awareness and Education. In Proceedings of the 2013 ACM SIGSAC Conference on Computer \& Communications Security (CCS '13), 915-928. https://doi.org/10.1145/2508859.2516753

19. Graham Dove, Caroline Emilie Lundqvist, and Kim Halskov. 2018. The Life Cycle of a Generative Design Metaphor. In Proceedings of the 10th Nordic Conference on HumanComputer Interaction (NordiCHI '18), 414-425. https://doi.org/10.1145/3240167.3240190

20. Ulrike Felt, Simone Schumann, Claudia G Schwarz, and Michael Strassnig. 2014. Technology of imagination: a cardbased public engagement method for debating emerging technologies. Qualitative Research 14, 2: 233-251. https://doi.org/10.1177/1468794112468468

21. Batya Friedman and David Hendry. 2012. The envisioning cards: a toolkit for catalyzing humanistic and technical imaginations. In Proceedings of the 2012 ACM annual conference on Human Factors in Computing Systems - CHI '12, 1145. https://doi.org/10.1145/2207676.2208562

22. Thomas M. J. Fruchterman and Edward M. Reingold. 1991. Graph drawing by force-directed placement. Software: Practice and Experience 21, 11: 1129-1164. https://doi.org/10.1002/spe.4380211102

23. Michael Golembewski and Mark Selby. 2010. Ideation Decks: A Card-based Design Ideation Tool. In Proceedings of the 8th ACM Conference on Designing Interactive Systems (DIS '10), 89-92. https://doi.org/10.1145/1858171.1858189

24. Mark Hall, Pablo Bermell-Garcia, Ranjit Ravindranath, and Christopher McMahon. 2017. Lessons learnt from experts in design rationale knowledge capture. DS 87-6 Proceedings of the 21st International Conference on Engineering Design (ICED 17) Vol 6: Design Information and Knowledge, Vancouver, Canada, 21-25.08.2017. Retrieved September 19, 2018 from https://www.designsociety.org/publication/39788/Lessons+le arnt+from+experts+in+design+rationale+knowledge+capture

25. Kim Halskov and Peter Dalsgaard. 2006. Inspiration Card Workshops. In Proceedings of the 6th Conference on Designing 
Interactive Systems (DIS '06), 2-11. https://doi.org/10.1145/1142405.1142409

26. Kristina Höök and Jonas Löwgren. 2012. Strong Concepts: Intermediate-level Knowledge in Interaction Design Research. ACM Trans. Comput.-Hum. Interact. 19, 3: 23:123:18. https://doi.org/10.1145/2362364.2362371

27. Eva Hornecker. 2010. Creative Idea Exploration Within the Structure of a Guiding Framework: The Card Brainstorming Game. In Proceedings of the Fourth International Conference on Tangible, Embedded, and Embodied Interaction (TEI '10), 101108. https://doi.org/10.1145/1709886.1709905

28. David G. Jansson and Steven M. Smith. 1991. Design fixation. Design Studies 12, 1: 3-11. https://doi.org/10.1016/0142694X(91)90003-F

29. Jussi Markus Kuittinen. 2008. Computer-Aided Game Design. University of Jyväskylä.

30. Annakaisa Kultima, Johannes Niemelä, Janne Paavilainen, and Hannamari Saarenpää. 2008. Designing Game Idea Generation Games. In Proceedings of the 2008 Conference on Future Play: Research, Play, Share (Future Play '08), 137-144. https://doi.org/10.1145/1496984.1497007

31. Joanna Kwiatkowska, Agnieszka Szóstek, and David Lamas. 2014. (Un)Structured Sources of Inspiration: Comparing the Effects of Game-like Cards and Design Cards on Creativity in Co-design Process. In Proceedings of the 13th Participatory Design Conference: Research Papers - Volume 1 (PDC '14), 3139. https://doi.org/10.1145/2661435.2661442

32. J. Lee. 1997. Design rationale systems: understanding the issues. IEEE Expert 12, 3: 78-85. https://doi.org/10.1109/64.592267

33. Nick Logler, Daisy Yoo, and Batya Friedman. 2018. Metaphor Cards: A How-to-Guide for Making and Using a Generative Metaphorical Design Toolkit. In Proceedings of the 2018 on Designing Interactive Systems Conference 2018 - DIS '18, 1373-1386. https://doi.org/10.1145/3196709.3196811

34. Andrés Lucero and Juha Arrasvuori. 2012. The PLEX Cards and its techniques as sources of inspiration when designing for playfulness. International fournal of Arts and Technology 6, 1: 22-43. https://doi.org/10.1504/IJART.2013.050688

35. Ewa Luger, Lachlan Urquhart, Tom Rodden, and Michael Golembewski. 2015. Playing the Legal Card: Using Ideation Cards to Raise Data Protection Issues Within the Design Process. In Proceedings of the 33rd Annual ACM Conference on Human Factors in Computing Systems (CHI '15), 457-466. https://doi.org/10.1145/2702123.2702142

36. A. MacLean, R. M. Young, and T. P. Moran. 1989. Design Rationale: The Argument Behind the Artifact. In Proceedings of the SIGCHI Conference on Human Factors in Computing Systems (CHI '89), 247-252. https://doi.org/10.1145/67449.67497

37. H. McGilp, C. Eckert, and C. Earl. 2016. Don't Look Back: The Paradoxical Role of Recording in the Fashion Design Process. In Proceedings of DRS2016: Design + Research + Society Future-Focused Thinking, 2521-2534. Retrieved September 18, 2018 from http://www.drs2016.org/proceedings/

38. Markus Montola, Jaakko Stenros, and Annika Waern. 2009. Pervasive Games: Theory and Design. CRC Press, Amsterdam; Boston.

39. Simone Mora, Francesco Gianni, and Monica Divitini. 2017. Tiles: A Card-based Ideation Toolkit for the Internet of Things. In Proceedings of the 2017 Conference on Designing
Interactive Systems (DIS '17), 587-598. https://doi.org/10.1145/3064663.3064699

40. Florian Mueller, Martin R. Gibbs, Frank Vetere, and Darren Edge. 2014. Supporting the Creative Game Design Process with Exertion Cards. In Proceedings of the SIGCHI Conference on Human Factors in Computing Systems (CHI '14), 22112220. https://doi.org/10.1145/2556288.2557272

41. Carman Neustaedter, Anthony Tang, and Tejinder K. Judge. 2013. Creating scalable location-based games: lessons from Geocaching. Personal and Ubiquitous Computing 17, 2: 335349. https://doi.org/10.1007/s00779-011-0497-7

42. Kenton O’Hara. 2008. Understanding Geocaching Practices and Motivations. In Proceedings of the SIGCHI Conference on Human Factors in Computing Systems (CHI '08), 1177-1186. https://doi.org/10.1145/1357054.1357239

43. Janne Paavilainen, Hannu Korhonen, Kati Alha, Jaakko Stenros, Elina Koskinen, and Frans Mayra. 2017. The PokéMon GO Experience: A Location-Based Augmented Reality Mobile Game Goes Mainstream. In Proceedings of the 2017 CHI Conference on Human Factors in Computing Systems (CHI '17), 2493-2498. https://doi.org/10.1145/3025453.3025871

44. Robin Roy and James Warren. 2018. Card-based Tools For Creative And Systematic Design. In Proceedings of the Design Research Society DRS2018 conference (TBC). Retrieved September 20, 2018 from http://www.drs2018limerick.org/

45. Jesse Schell. 2008. The Art of Game Design: A book of lenses. CRC Press, Amsterdam; Boston.

46. Clare Southerton. 'Zombies, Run!': Rethinking immersion in light of nontraditional gaming contexts.

47. Davide Spallazzo and Ilaria Mariani. 2018. Location-Based Mobile Games: Design Perspectives. Springer International Publishing. Retrieved September 16, 2018 from //www.springer.com/gb/book/9783319752556

48. B. Thomas, B. Close, J. Donoghue, J. Squires, P. De Bondi, M. Morris, and W. Piekarski. 2000. ARQuake: an outdoor/indoor augmented reality first person application. In Digest of Papers. Fourth International Symposium on Wearable Computers, https://doi.org/10.1109/ISWC.2000.888480

49. Hongwei Wang, Aylmer L. Johnson, and Rob H. Bracewell. 2012. The retrieval of structured design rationale for the reuse of design knowledge with an integrated representation. Advanced Engineering Informatics 26, 2: 251-266. https://doi.org/10.1016/j.aei.2012.02.003

50. Mark Weiser and John Seely Brown. 1997. The Coming Age of Calm Technology. In Beyond Calculation: The Next Fifty Years of Computing, Peter J. Denning and Robert M. Metcalfe (eds.). Springer New York, New York, NY, 75-85. https://doi.org/10.1007/978-1-4612-0685-9_6

51. Richard Wetzel. 2014. Introducing Pattern Cards for Mixed Reality Game Design. Retrieved September 18, 2018 from http://www.orchid.ac.uk/eprints/id/eprint/208.html

52. Richard Wetzel, Rod McCall, Anne-Kathrin Braun, and Wolfgang Broll. 2008. Guidelines for Designing Augmented Reality Games. In Proceedings of the 2008 Conference on Future Play: Research, Play, Share (Future Play '08), 173-180. https://doi.org/10.1145/1496984.1497013

53. Richard Wetzel, Tom Rodden, and Steve Benford. 2017. Developing Ideation Cards for Mixed Reality Game Design. Transactions of the Digital Games Research Association 3. https://doi.org/10.26503/todigra.v3i2.73 
54. Christiane Wölfel and Timothy Merritt. 2013. Method Card Design Dimensions: A Survey of Card-Based Design Tools. In Human-Computer Interaction - INTERACT 2013 (Lecture Notes in Computer Science), 479-486.

55. José P. Zagal, Michael Mateas, Clara Fernández-vara, Brian Hochhalter, and Nolan Lichti. 2005. Towards an Ontological Language for Game Analysis. In in Proceedings of International DiGRA Conference, 3-14.

56. 2018. The Moral-IT \& Legal-IT Decks. Lachlan's Research. Retrieved September 20, 2018 from https://lachlansresearch.com/the-moral-it-legal-it-decks/

57. Method Cards. Retrieved September 20, 2018 from https://www.ideo.com/post/method-cards

58. About Top Trumps | Top Trumps | Play free online games and discover the world's coolest card game. Retrieved September 21, 2018 from http://www.toptrumps.com/abouttop-trumps/ 